\title{
Stensen's duct injuries: the role of sialendoscopy and adjuvant botulinum toxin injection
}

\author{
Tomasz Kopeć, Małgorzata Wierzbicka, Witold Szyfter \\ Ear Nose Throat Department, Poznan University of Medical Sciences, Poland
}

Videosurgery Miniinv 2013; 8 (2): 112-116 DOI: $10.5114 /$ wiitm.2011.32851

\begin{abstract}
Introduction: Stensen's duct injuries are uncommon but troublesome sequelae of facial surgery or other external traumas.

Aim: To investigate the feasibility of sialendoscopic control of Stensen's duct in iatrogenic injuries and the efficiency of botulinum toxin adjuvant therapy.

Material and methods: In 2008 and 2010, 5 patients with parotid sialoceles or fistulas, infrequent complications after plastic surgery or trauma, were treated in a single institution, Poznan University of Medical Sciences ENT Department. The group consisted of 5 patients with diagnosed Stensen's duct injuries, which were post-surgery and post-traumatic sequelae. All were treated by means of open surgery. Botulinum toxin injection was administered during the procedure to decrease the saliva secretion and to improve the healing process. A sialendoscopy was performed to control the lumen of the junction after the duct injury was repaired.

Results: Complete healing of the fistulas and sialoceles after the reparative surgery followed by a single botulinum toxin application was observed in all patients within 10-14 days. No side effects were noticed.

Conclusions: Our findings suggest that sialendoscopy is a valuable tool and an important step of control in the surgery of parotid duct injuries and the injection of botulinum toxin is an effective and safe second-line treatment.
\end{abstract}

Key words: Stensen's duct injuries, sialendoscopy, botulinum toxin.

\section{Introduction}

Stensen's duct injuries manifesting with sialoceles or salivary fistulas are uncommon but troublesome sequelae of facial surgery or other external traumas. The conservative approach is rarely successful; thus open surgery has to be finally performed. A sialendoscopy first to diagnose and finally to control the lumen of the duct and the repaired junction after the procedure can be helpful. Botulinum toxin injection administered during the procedure to decrease the secretion of saliva can improve the healing process. The therapeutic application of botulinum toxin has been extended to various clinical disorders, including salivary secretory diseases [1-5]. In the isolated pathology of one parotid, especially when connected with salivary secretion leakage, the method could be a valuable alternative to oral antisialogogues and anticholinergic medications that inhibit total neural stimulation [6-9].

\section{Aim}

The aim of the study was to analyse treatment of Stensen's duct injuries: the role and technique of open surgery, feasibility of sialendoscopic control of 
Stensen's duct, and the value of adjuvant botulinum toxin application.

\section{Material and methods}

In a single institution, tertiary teaching centre, Poznan University of Medical Sciences ENT Department, between 2008 and 2010, 351 patients with major salivary gland pathology were treated (186 with parotid tumours, 30 with miscellaneous parotid gland disorders) and among them 114 sialendoscopies were performed. We would like to focus on a rare entity of parotid gland pathology, i.e. post-surgery and posttraumatic Stensen's duct injuries. Data were obtained from 5 patients with parotid sialoceles or fistulas that occurred as complications after parotid trauma with Stensen's duct rupture. In this retrospective review of cases, patients with parotid duct injuries were diagnosed by means of clinical examination, ultrasonography, magnetic resonance imaging (MRI) and sialendoscopy. After a short time of conservative treatment all were qualified for open surgery, followed by sialendoscopic control and botulinum administration. Our research was approved by the Bioethical Commission. Sialendoscopy was performed using semirigid sialendoscopes with external diameter of $1.1 \mathrm{~mm}$, $1.3 \mathrm{~mm}$ and $1.6 \mathrm{~mm}$ (Karl Storz, Tuttlingen, Germany). The first attempt was made intraoperatively and aimed at good visualization of the ductal system, mainly to show the point of the duct rupture. The final examination in the postoperative period showed the surgery outcome, i.e. the sutured duct.

The main goal of the botulinum treatment was to temporarily decrease saliva production to assist the healing of the glandular tissue. We used Xeomin (NT-201; Merz Pharmaceuticals GmbH, Germany), containing $100 \mathrm{MU}$ per bottle diluted in $2 \mathrm{ml}$ of $0.9 \%$ sodium chloride solution. For each patient, 20-40 mouse units $(\mathrm{MU})$ were injected into the parotid gland or its residual tissue, fractionated into 2 to 4 doses. The number, location of injection points and total dose depended on the previous surgery and the amount of parotid tissue that was excised and that which remained. To decrease the risk of facial nerve paresis, the injections were performed under the control of colour ultrasonography imaging. The needle was placed in the remaining part of the superficial lobe parenchyma, at a safe distance from the lumen of the vessels examined using ultrasonography.
The first patient, a 47-year-old woman with a duct injury sustained during a face lift, came to our department 4 weeks after the aesthetic procedure with considerable swelling in the cheek, tenderness, and an erythematous skin rash. Compression bandaging, serial aspiration, oral antibiotics and anticholinergic medication were administered for 4 weeks by the plastic surgeon, with no effect. After admission into our department, non-surgical treatments were continued for another week, but the local condition worsened, and the decision was made to revise the wound. The buccal flap was elevated, and the proximal and distal stumps of the duct were released from the scars and sutured after the insertion of a microcatheter into the lumen. After the 6-hour procedure, $40 \mathrm{U}$ of botulinum toxin was injected into four sites in the gland parenchyma. The micro-catheter was removed on the $7^{\text {th }}$ day by means of sialendoscopy. During the postoperative period, a small, $1-\mathrm{cm}$ sialocele developed on the $14^{\text {th }}$ day due to a dietary fault; compression bandaging and oral antibiotic were administered for 5 days. Twenty-one days after surgery, sialendoscopic control of the duct and the junction point was satisfactory; Photo 1 (Karl Storz Co. $\mathrm{GmbH}$, Tuttlingen, Germany).

A second patient, a 22-year old man, had a face injury sustained from a glass bottle 6 weeks earlier. The wound was sutured by a general surgeon $24 \mathrm{~h}$ after the accident. On admission to the department, he presented a 2-cm-deep open wound in the middle part of the cheek with salivary fistulas and pieces of glass inside the wound. Ultrasonography and MRI were performed. He was treated with a revised surgery. The superficial lobe was exposed, two lower facial nerve branches were identified in a retrograde manner and seven pieces of broken glass removed from the gland. Scar tissue and the parenchyma of the lateral part of the gland were partially removed. The parotid duct was cannulated through the papilla, released from the scars and micro-sutured end to end without tension. During treatment, the patient refused to have the dressing replaced and did not obey the recommended diet, and consequently, we decided to apply $30 \mathrm{U}$ of botulinum toxin into three sites (the toxin was not administered into the previously resected anterior quadrant). The wound healed by primary intention. Controlled sialendoscopy was not undertaken because the patient left the hospital on the $7^{\text {th }}$ day post-surgery and has been free of symptoms for the past 8 months. 


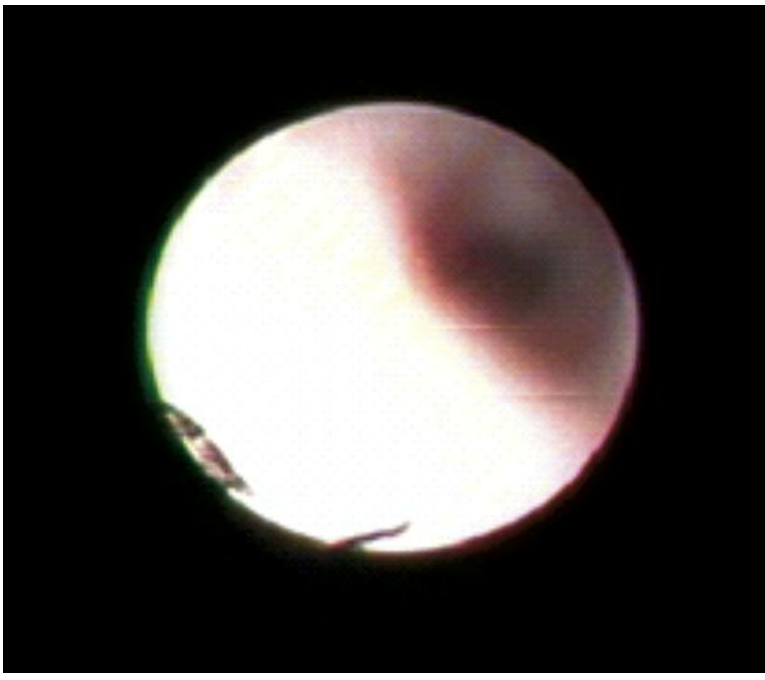

Photo 1. Sialendoscopic view of reconstructed Stensen's duct at the junction point

In the third and fourth case (females aged 56 and 58 , respectively), parotid duct incisions were made to remove huge stones that were $2.5 \mathrm{~cm}$ and $3 \mathrm{~cm}$ in diameter, respectively. The duct incisions were made along the long axis and were long enough to avoid spontaneous rupture during the removal of the stones. In both cases, the stones were firmly attached to the inlet of the duct wall and were difficult to remove. In each case, the incision was closed by 6 micro-sutures, and $40 \mathrm{U}$ of botulinum toxin was injected simultaneously into 4 sites. Sialendoscopic control of the duct was satisfactory (Photo 2).

In the fifth patient, the buccal part of the duct was resected during the extension surgery of an aggressive basal cell cancer of the middle part of the face and right cheek, which was $10 \mathrm{~cm}$ in diameter. The duct was prepared at the anterior border of the parotid gland and was resected with the infiltration of the buccinator muscle and the vestibule of the mouth. The stump of the duct was sutured into the remnant of the reconstructed oral cavity mucosa. The free forearm flap was used during the reconstruction of the mouth vestibule inlet and the upper lip. In this case, dressings were contraindicated. To reduce the parotid secretion, $40 \mathrm{U}$ of botulinum toxin was injected into four sites.

Four patients who underwent a primary repair of Stensen's duct recovered within 7-21 days. A patient who showed complications after a face lift and who was operated on 5 weeks after a duct injury recovered within 21 days; another patient with a foreign

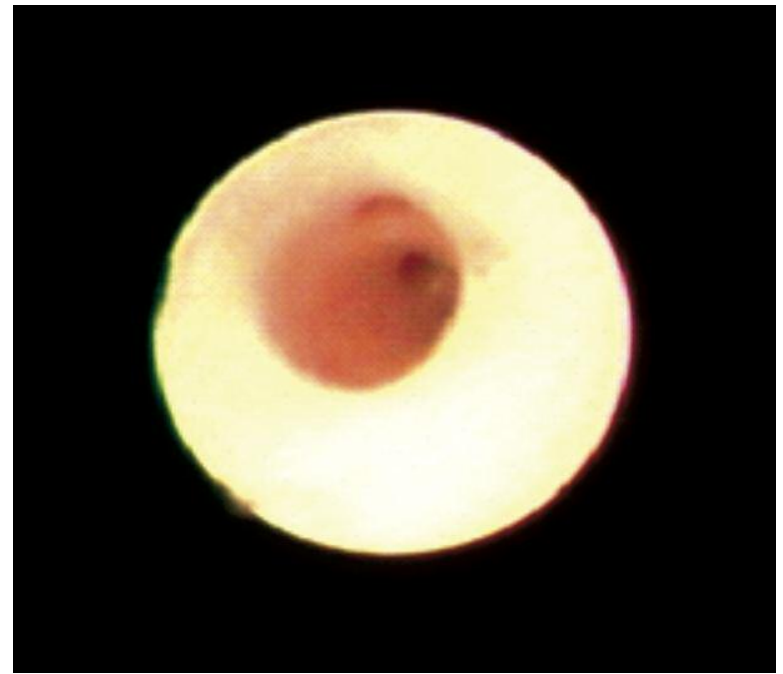

Photo 2. Sialendoscopic control after removal of a huge stone and duct wall repair

body impacted in the cheek recovered within 10 days, and 2 patients who underwent a duct incision for the extirpation of huge stones recovered in 8 and 7 days. In a fifth patient who had undergone surgery for an aggressive cancer of the middle part of the face, the main goal of the injection (i.e., the reduction of parotid secretion into the reconstructed inlet of the mouth vestibule and the upper lip) was achieved after 3 weeks of the treatment. In all patients, the open surgery was followed by botulinum toxin injection. Sialendoscopy was performed in selected cases to control the lumen of the duct and point of the junction (the first, third and fourth patient; Table I).

\section{Discussion}

Sialoceles are characterised by extravasation of saliva into the surrounding soft tissue. Idiopathic sialoceles are rare, but post-traumatic, including iatrogenic sialoceles, are common surgical complications and occur predominantly in the parotid gland $[7,10]$. The occurrence of parotid fistulas is relatively rare as a complication of parotidectomy or as a result of a penetrating injury to the parotid gland combined with parotid duct rupture. Salivary flow through the epithelium-coated channel into the skin opening interferes with wound healing. We have described two fistulas that resulted from the transection of Stensen's duct, one performed after a face lift and one external injury caused by a shattered glass bottle. Marchese-Ragona et al. described three cases of 
Table I. Patients with Stensen's duct injuries

\begin{tabular}{|c|c|c|c|c|c|c|c|c|}
\hline \multicolumn{2}{|c|}{ Patient } & \multirow[t]{2}{*}{ Reason } & \multicolumn{2}{|c|}{ Day of } & \multicolumn{2}{|c|}{ Number of } & \multirow{2}{*}{$\begin{array}{l}\text { Sialendo- } \\
\text { scopy }\end{array}$} & \multirow{2}{*}{$\begin{array}{l}\text { Day of } \\
\text { healing }\end{array}$} \\
\hline $\begin{array}{l}\text { Sex } \\
\text { (F/M) }\end{array}$ & $\begin{array}{c}\text { Age } \\
\text { [years] }\end{array}$ & & $\begin{array}{l}\text { complication } \\
\text { occurrence }\end{array}$ & $\begin{array}{c}\text { Botox } \\
\text { injection }\end{array}$ & MU & points & & \\
\hline $\mathrm{F}$ & 47 & Face lift surgery & 7 & 35 & 40 & 4 & Yes & 14 \\
\hline M & 22 & Glass injury & 8 & 42 & 30 & 3 & No & 10 \\
\hline $\mathrm{F}$ & 56 & Removal of impacted stone & 0 & 0 & 40 & 4 & Yes & 8 \\
\hline $\mathrm{F}$ & 58 & Removal of impacted stone & 0 & 0 & 40 & 4 & Yes & 7 \\
\hline M & 56 & Basal cell cancer & 0 & 0 & 40 & 4 & No & 14 \\
\hline
\end{tabular}

F-female, $M$ - male

iatrogenic fistula treated in the Padua ENT Department [9]. Patients with parotid duct injuries can be divided into cases that are recognised at the time of surgery and those that have a delayed diagnosis [11]. If a parotid duct injury is recognised at the time of surgery, primary repair with minimal tissue loss is the treatment of choice [12]. Simple wound exploration is enough to perfect the visualisation of the duct, in contrast to the patients who underwent delayed surgery. In the set of cases presented here, two cases (an injury sustained during a face lift and an injury by a piece of glass) were not recognised immediately (i.e., at the time of the plastic surgery and at the time that the cheek wound was sutured by the general surgeon). In both cases, the tear of the duct was not minute and the duct was completely cut through the whole diameter, and was difficult to treat without surgery. The duct repair was performed later in these 2 cases, during the $5^{\text {th }}$ and $6^{\text {th }}$ weeks, respectively. In both cases, the precise localisation of duct injury was possible after a long-lasting scar preparation under the microscope. The parotid ducts were cannulated as described by Steinberg in order to better guide the distal stump [12]. Nearby branches of the facial nerve in both cases were identified and left untouched; there was no need to stain with methylene blue for facial nerve identification, as suggested by Nahlieli and Levy [13]. In our experience, although the leakage of the dye from the injured parotid duct confirmed the lesion, the orientation of the duct in coloured tissues is more difficult.

Intra-parotid injections of botulinum toxin are a well-known means of reducing parotid gland secretions because these injections block the presynaptic release of acetylcholine at the neuromuscular junc- tion [14]. The therapeutic application has been extended to various clinical disorders, including salivary secretory diseases [1-5]. In the isolated pathology of one parotid, especially when connected with salivary secretion leakage, the value of the method is even higher than oral antisialogogues and anticholinergic medications that inhibit the total neural stimulation. Local administration eliminates unpleasant anticholinergic side effects such as mouth dryness, blurred vision, photophobia, tachycardia, constipation and urinary retention [15]. The use of a local cholinergic block by way of botulinum toxin injection diminishes the need for other methodologies. The conservative method reduced the ability of patients to take food orally and required intravenous feeding. Surgical procedures, such as parotid denervation by avulsion of the auriculotemporal nerve, tympanic neurectomy, tympanic nerve section or even total parotidectomy and radiotherapy, which was advocated at the end of the $20^{\text {th }}$ century, are no longer used [16]. The total dose of botulinum toxin that is recommended for the treatment of one parotid differs according to different authors. Marchese-Ragona et al. [9] used $5 \mathrm{MU}$ per site, $10 \mathrm{MU}$ for two different sites or $20 \mathrm{MU}$ for three sites, whereas Ellies et al. [14] used 22.5 MU for three sites, Capaccio et al. [7] used $60 \mathrm{MU}$ and Arnaud used up to $100 \mathrm{MU}$. Lim et al. [8] recommended that the neurotoxin be administered on the $7^{\text {th }}$ day, whereas Marchese-Ragona et al. [9] recommended that the neurotoxin be administered 10 days after unsuccessful conservative treatment. In our experience, the intraparenchymal injection of botulinum toxin could be administered earlier, immediately after the occurrence of sialoceles or fistulas or intraoperatively. The botulinum toxin injec- 
tions support the basic treatment of iatrogenic fistulas or sialoceles, which consists of pressure dressings and a prescribed diet. Shortening the time of parotid fistula closure is important to avoiding wound dehiscence and infection. Arnaud et al. [1] recommend the use of botulinum toxin injections as first intention management for the described iatrogenic complications. Sialendoscopy first to diagnose and finally to control the lumen of the duct and the repaired junction after the procedure can be helpful. This minimally invasive technique enables good visualisation of the ductal system. Nahlieli et al. [13] have recently described the exclusively endoscopic repair of the dissected Stensen's duct with the use of the inserted stent; the microsutures were applied in this kind of approach. The administration of Botox neurotoxin seemed to play an important role in the improvement of the final healing process due to the temporary reduction of gland secretion. Sialendoscopy is not indispensible, but it is a helpful tool for confirming proper duct healing and for the exclusion of stenosis at the junction point of the reconstructed parotid duct.

\section{References}

1. Arnaud S, Batifol D, Goudot P, Yachouh J. Non-surgical management of parotid gland and duct injuries: interest of botulinum toxin. Annales de Chir Plastiq Estetiq 2008; 53: 36-40.

2. de Bree R, van der Waal I, Leemans R. Management of Frey syndrome. Head Neck 2007; 29: 773-8.

3. Bomeli SR, Shaun CD, Johnson JT, Walvekar RR. Management of salivary flow in head and neck cancer patients: a systematic review. Oral Oncology 2008; 44: 1000-8.

4. Breuer T, Ferrazzini A, Grossenbacher R. Botulinumtoxin A zur Therapie traumatischer Speichelfisteln. HNO 2005; 54: 385-93.

5. Sriskandan N, Moody A, Howlett DC. Ultrasound-guided submandibular gland injection of botulinum toxin for hypersalivation in cerebral palsy. Br J Oral Maxillofac Surg 2010; 48: 58-60.

6. Vargas H, Galati LT, Parnes SM. A pilot study evaluating the treatment of postparotidectomy sialoceles with botulinum tox in type A. Arch Otolaryngol Head Neck Surg 2001; 127: 339-40.

7. Capaccio P, Torretta S, Osio M, et al. Botulinum toxin therapy: a tempting tool in the management of salivary secretory disorders. Am J Otolaryngol 2008; 29: 333-8.

8. Lim YC, Choi EC. Treatment of an acute salivary fistula after parotid surgery: botulinum toxin type A injection as primary treatment. Eur Arch Otorhinolaryngol 2008; 265: 243-5.

9. Marchese-Ragona R, Marioni G, Restivo DA, Staffieri A. The role of botulinum toxin in postparotidectomy fistula treatment. A technical note. Am J Otolaryngol 2006; 27: 221-4.

10. Capaccio P, Cuccarini V, Benicchio V, et al. Treatment of iatrogenic submandibular sialocele with botulinum toxin: case report. Br J Oral Maxillofac Surg 2007; 45: 415-7.

11. Krishnan RS, Clark DP, Donnelly HB. The use of botulinum toxin in the treatment of a parotid duct injury during Mohs surgery and review of management options. Dermatol Surg 2009; 35: 941-7.

12. Steinberg MJ, Herrera AF. Management of parotid duct injuries. Oral Surg Oral Med Oral Pathol Oral Radiol Endod 2005; 99 : 136-41.

13. Nahlieli O, Levy Y. Intravital staining with methylene blue as an aid to facial nerve identification in parotid gland surgery. J Oral Maxillofac Surg 2001; 59: 355-6.

14. Ellies M, Gottstein U, Rohrbach-Volland S, et al. Reduction of salivary flow with botulinum toxin: extended report on 33 patients with drooling, salivary fistulas, and sialadenitis. Laryngoscope 2004; 114: 1856-60.

15. Guntinas-Lichius O. Management of Frey's syndrome and hypersialorrhea with botulinum toxin. Facial Plastic Surg Clin North Am 2003; 11: 1856-60.

16. Majid OW. Clinical use of botulinum toxins in oral and maxillofacial surgery. Int J Oral Maxillofac Surg 2010; 39: 197-207.

Received: 19.04.2012, revised: 17.12.2012, accepted: 27.12.2012. 